\title{
Exploration of the path of art education resources in Colleges and universities in Jiangxi
}

\author{
LAI Wenqing ${ }^{1,2}$ \\ ${ }^{1}$ College of Applied Science, Jiangxi University of Science and Technology, Ganzhou 341000, China; \\ ${ }^{2}$ Digital Research Institute of Hakka Culture, Ganzhou 341000, China
}

\begin{abstract}
Art education in colleges and universities is an important part of China's higher education. It takes art as the content and educates people. Through educational activities, it fosters college students to form correct aesthetic concepts, improve their personal personality, and stimulate their imagination and creativity. The integration of art education into Hakka cultural inheritance has the problem of compatibility between the law of cultural inheritance and the law of education. Efforts should be made to activate static local cultural resources into dynamic educational and cultural capital. Hakka culture curriculum system should be integrated with traditional cultural characteristics and art education concepts. The contents should be closely related to art education, and the Hakka spirit of simplicity and diligence should be transmitted through the connotation of Hakka culture. The "cultural resources into curriculum resources", "cultural elements into cultural creativity" double path teaching implementation, to achieve the value of Hakka cultural resources inheritance.
\end{abstract}

\section{Introduction}

Art Education in Colleges and universities is an important part of China's higher education. It takes art as its content and aims at educating people. Through educational activities, it cultivates college students to form correct aesthetic concepts, improve their personality, and stimulate their imagination and creativity. Therefore, in recent years, the Ministry of education has attached great importance to art education in Colleges and universities. The guiding outline of Higher Art Education issued by the Ministry of education in 2009 clearly points out that art education is included in the required courses in undergraduate colleges, and each college student must obtain two credits of art education courses before graduation. In art education, we should strive to launch a number of courses and teaching materials with high quality and strong characteristics, constantly improve the quality of teaching, and strengthen the construction of teaching staff and art resources in art education.

In 2018, President Xi Jinping attended a symposium to mark the fifth anniversary of the Belt and Road initiative and delivered an important speech. He called for dialogue, consultation, joint contribution, win-win cooperation, exchanges and mutual learning to deepen and deliver real benefits to the people. Through the maritime Silk Road, Hakka people have expanded their development space, and Hakka culture has been spread abroad. The development of Hakka culture should seize the historical opportunity of the new era, make full use of the historical relationship between Hakka and maritime silk road, grasp the national " the Belt and Road initiative " development strategy, and explore and integrate the historical and cultural resources of Hakka ancestral land and overseas Hakka. It is also necessary to make full use of the advantages of Guangdong, Hong Kong and Macao Bay area, which is a world-class urban agglomeration and an important space carrier for participating in global competition, to stand at the bridgehead of Jiangxi, and to integrate the excellent local culture of the main Hakka gathering areas (Southern Jiangxi, Eastern Fujian, western Guangdong, Hong Kong, Macao and overseas) into local education, so as to form unique regional cultural characteristics.

The integration of Hakka culture into art education in Colleges and universities has the problem of cultural inheritance law, education law and compatibility between laws. To solve this problem, schools, local governments and society should work together to complete the cultural inheritance work, so as to jointly construct the art education system in Colleges and Universities under the guidance of Hakka cultural resources. Taking Hakka culture curriculum system as an example, through the optimization of art education curriculum, this paper constructs a dual path teaching method of "transforming cultural resources into curriculum resources" and "transforming cultural elements into cultural and creative products", so as to realize the value of inheritance of Hakka cultural resources. 


\section{The present situation of art education and teaching in Jiangxi Universities}

Taking a university in Jiangxi Province as an example, from 2010 to 2018, a total of 55 public elective courses with 60 credits and 976 class hours have been set up, and each student has to take 6 credits of public elective courses; the courses include 23 Erya online courses and 32 selftaught courses; the credit setting is 1 , the class hours are 16 , and the starting semester is from the second to the sixth semester, that is, from freshman to junior. The courses offered are mainly appreciation and liberal education. There are 12 appreciation courses: literature appreciation, music appreciation, dance appreciation, calligraphy appreciation, film and television appreciation, poetry appreciation, art appreciation, drama appreciation and other courses; 20 liberal education courses: College Chinese, college students' etiquette, ancient Chinese history, public relations, western literature theory, host art and other courses. Although the courses are very rich, most students choose public courses based on whether the exams are easy or not and whether it is easy to get credits. Some students are interested in the content of the course, but the classroom teaching is just to play a few videos, listen to a few foreign songs, and follow the teacher to understand the music theory. The appreciation of art works is just a kind of introduction to the creator, and appreciation of the content and form of the theme and theme of the art works, Students' perception of the course is only a shallow level of appreciation, and does not go deep into the artistic appeal of works of art, not to mention the deep connotation of art works, as well as the related historical background, humanistic background, social background and aesthetic connotation, etc. Not to mention the feeling of crying with joy and passion.

Most of the art education courses in Colleges and universities are the same, so it is easy to judge the good or bad of an art work only from the self-perception, and often ignore the connotation and role of the aesthetic function of art education. School art education is the main way and content of aesthetic education. Jiangxi has rich local cultural resources. It integrates Hakka culture into art education in Colleges and universities. In the aspects of excellent local traditional culture education, value education, ideological education, etc., the carrier of aesthetic education in Colleges and universities and the characteristics of Hakka culture should be brought into play, so that students can be from admirers to receivers, and then creators, and eventually will be sharers and appreciators.

\section{Current situation of Hakka cultural resources}

Local characteristic culture is a kind of culture that has been formed in a specific area for a long time with historical inheritance, regional uniqueness and nonreplication. Gannan of Jiangxi Province is the area with the largest number of Hakkas. After many migrations and the collision of local culture, a large number of precious historical and cultural resources have been preserved in this land. This paper mainly combs the Hakka cultural resources from the dominant forms.

\subsection{Stories of Hakka literati in Gannan}

Hakka has always had the activities of many literati and celebrities, which has made great contributions to the rise of local culture and has been handed down to this day. Each of these celebrity stories is a true portrayal of Hakka culture. For example, Wenqing road in Ganzhou City, named after the posthumous titles of Song Dynasty, Cuiwei mountain of Ningdu county where the nine sons of Wei Xiyi Tang are located, as well as the interesting stories written by Wang Yangming, Zhou Dunyi, Cheng Yi, Zhang Jiuling, Zhong Shaojing and Ouyang Xiu, as well as interesting stories written by local sages. How many people in ancient and modern times have written a lot of writing about Hakka precious cultural knowledge is an important resource for local cultural heritage. It is necessary to transform it into educational resources. In the process of art education, we should make use of people and things around us to carry out cultural activities and teaching, so as to promote students' understanding of the characteristics of culture affecting people and its influence on themselves, and promote the unity of ideological and aesthetic education in art education and teaching.

\subsection{Gannan Hakka folk activities}

Hakka folk culture can be described as rich and colorful, antique, which is derived from the farming and worship of ancestors and gods of multi-cultural performance, with a unique local flavor.The folk activities that have been handed down to this day show most Hakka people's yearning for life and their love for life one by one. For example, festivals, weddings and funerals, large-scale construction, river crossing and bridge building and other life scenes all attach great importance to the sense of ceremony, and usually appear in the form of activities with performances carried out by villagers under specific links. For example, Yudu's "plaque", Ningdu's "cut chicken", Ganxian county's "burning tower" in the Mid-Autumn Festival. Along the way, musical instruments were blown and beaten, and firecrackers rang wherever the team went. The crowd was even more on three floors and three outside. It was very lively. Many college students live and study in the place where they live and study in the past four years from entering school to graduation. They can make effective use of local folk culture, integrate into the classroom through art education, campus culture and other ways, integrate into campus activities, and feel the richness and diversity of local culture. This will be a heavy sum of students' life wealth and the value of integrating local culture into art education. It plays an important role in feeling and spreading local culture.

\subsection{Gannan Hakka traditional architecture}

The Hakka ancestors and the Hakka people, including the present Hakka people, are almost devout to the concept of home. The materialization of the concept of home and 
family destination is presented in the form of architecture. Traditional buildings are mainly Hakka dwellings, Hakka Ancestral Halls, and some ancient villages, bridges, towers and archways. According to the data of the third national survey of immovable cultural relics, there are 62 Hakka enclosed houses at all levels under protection, and there are also a large number of unprotected enclosed houses and ancestral halls. The enclosed houses are mainly concentrated in "three South and one far", namely Longnan, Quanyuan, Dingnan and Anyuan counties. For example, there are Xulaosi's Guanxi new enclosed houses; Yanyi enclosed houses of Yang village in Longnan, which can be seen from the roadside of expressway; Wushi enclosed houses of Longnan, which looks unbreakable; The tiger shape enclosed houses in Dingnan county, which has the appearance of carton tiger; Dingnan Mingyuan No.1 enclosed houses, which has three hard roofs; and Quanyuan Yaxi enclosed houses, where Hong Kong women live. Most of the enclosed houses have been protected. Some have been developed into scenic spots, some have been repaired and restored to their original appearance. Some Aborigines have moved out of the enclosed houses, and many people continue to live in the enclosed houses. Gannan has always been called a blessed land by Hakkas. Every year during the Qingming Festival, many descendants of Hakka at home and abroad will return home to worship their ancestors. The family ancestral hall is a fixed place for ceremonies to place their worship on their ancestors. This is also a manifestation of Hakka's clan consciousness and unity. At present, there are many ancestral halls in Gannan in different periods, such as Ming and Qing Dynasties. Each family ancestral hall is built in modern times. There are also many imitations of the ancients. They are all carved beams and painted buildings, which are unique.

\subsection{Gannan Hakka folk art}

Gannan Hakka folk art is rich and colorful. Because it is located in the mountainous area and the economy is relatively backward, many folk arts can be preserved. The existing folk art, paper cutting, opera, drama, folk songs and music, traditional song and dance lantern, sculpture, embroidery and other art forms. For example, Liu Shenghan, the inheritor of Hakka lanterns in Tian village, Ganxian County, is a walking lantern Museum. His family displays and stores picture books, skeletons and lamp samples for many years. All parts are numbered according to categories or technological processes. He is often invited by colleges and universities to carry out local cultural promotion activities. He is deeply loved by students and not only likes this traditional technology. Students not only like the cultural edification brought by this traditional skill, but also like the inner feeling of bringing traditional culture into life in the process of handwork. Such examples cannot be enumerated. These unique Hakka art in Gannan permeates and affects all aspects of life. It has a subtle influence on our life in a lively form. The excavation of Hakka Literature and art resources can add a charm to art education and teaching.

\subsection{Gannan Hakka thought}

In the process of migration and development, Hakkas have formed the ideas of advocating culture and education, advocating frugality, patriotism and loving the country. They generally attach importance to the value orientation of culture and education, especially respect the cultural people. The reason why Hakkas form the social atmosphere of advocating culture and education may be influenced by the survival of farming and the development of reading. These ideas and spirits have rich connotation and various forms. If they are fully integrated and utilized in the teaching process, they can greatly arouse students' interest and enthusiasm, and provide rich teaching resources and sources for cultural education. The combination of theory and practice is the highest level of learning, so that students can understand the culture of their hometown and be full of confidence in Hakka culture, so as to urge them to discover, analyze and solve problems from the perspective of life, and stimulate their interest in learning.

\section{On the process of transforming Hakka cultural resources into art education resources}

The general office of the Ministry of education pointed out in the notice of "the summary of the national exchange meeting on school art education work experience", that the development goal of school art education in 2020 should be: to achieve the benefit of all art education, to provide rich and high-quality art education, to build a complete system of art education. In order to achieve the above goals, we should deepen the reform of art education and teaching, improve the quality of art education in an all-round way, expand the benefit range of art activities, improve the level of art activities, strengthen the construction of campus culture, create a good educational environment, strengthen the construction of art teachers, improve the quality of art teachers in an all-round way, optimize the allocation of art education resources to ensure the necessary conditions of art education. We should strengthen teaching research and scientific research, promote the healthy development of art education, focus on promoting art education in rural schools, and promote the balanced development of art education.

According to the spirit of the meeting minutes, combined with Hakka cultural resources, this paper sorts out several selective principles of transforming Hakka cultural resources into art education resources:

\subsection{The subjective and objective selection of Hakka cultural resources.}

The purpose of the transformation of Hakka cultural resources is to achieve the teaching goal of art education. However, in the face of the diversity and regionalism of local culture, some contents have been divorced from the practical significance or too abstract to meet the requirements of art education. Therefore, the materials that cannot effectively serve the art education curriculum and 
affect students' cognition can be saved as the form of course material resources. Some very vivid and rich resources should be treated differently according to the characteristics of colleges and universities, teaching requirements, professional characteristics and students' hobbies. For example, engineering students in science and engineering colleges have less contact with humanities and social sciences courses than art students in art colleges. They choose to transfer Hakka cultural resources such as arts and crafts as well as aesthetics into art education courses. For example, "the construction technology of Hakka enclosed houses in Gannan" starts from the knowledge points of architecture, anthropology, design and other disciplines. The degree of attention is obviously higher. In art colleges and universities, local intangible cultural heritage courses, such as Nuo culture, are set up to create more cultural and artistic works from the perspectives of modeling design, graphic design, performance and costume design, combined with the specialty of art students. Therefore, we must adhere to the principle of selectivity in the process of its development and utilization.

\subsection{In line with the guiding ideology of art education.}

The selected Hakka cultural resources must be in line with the guiding ideology of art education. The understanding of art education, the dissemination of beautiful culture, the beauty of human nature and the yearning for a better life are in line with the development direction of contemporary aesthetic concepts. Choosing educational resources can enlighten students. Through guiding students to analyze various cultural phenomena and trends of thought, appreciate the essence of different national cultures, establish a high degree of cultural consciousness and cultural self-confidence, and promote students' all-round development.

\subsection{Meet the requirements of art education curriculum.}

Contemporary art education aims to improve humanistic quality and cultivate innovative talents, which requires the selected Hakka cultural resources to meet the overall teaching objectives of art education. Through the selection of appropriate Hakka cultural resources, we can break through the key and difficult points of teaching, and develop, integrate and utilize them. For example, in carrying out the "local excellent traditional culture", students need to understand the necessity and significance of carrying forward the fine traditional culture and understanding the significance of General Secretary Xi Jinping's statement that "without a high degree of cultural confidence, there will be no great rejuvenation of the Chinese people". In the course arrangement, the teacher will submit the background information about the origin, historical migration times and routes of Hakkas from the academic circles to the students. The students will form a research group and form a research report through field investigation. The video format with illustrations and texts will be used to assist the explanation. In the research process, the understanding and value identification of "promoting the excellent local traditional culture" will be formed. The teaching objective has been completed and the teaching purpose has been realized with pertinence and effectiveness.

\subsection{Close to the students' life and combine with the actual cultural resources.}

Through the investigation, the author learned that art education in Jiangxi universities is mostly arranged from the first semester to the third semester. During this period, students' acceptance of new things is very high. Many people's ideas are developing and maturing in this period. Many thoughts and values are imperceptibly influencing the future work and life. Some of the students are actively exploring through practice in the aspects of self-cultivation physical exercise, making friends, dealing with people and other aspects in the University; some students are studying hard every day, receiving information from the classroom and the Internet; some students muddle along in University, aimlessly, and are not interested in anything. Combined with the characteristics of these students, we can improve the vividness and interest of the course, and mobilize students to actively participate in the transformation of Hakka culture curriculum resources. Using Hakka cultural resources in the process of art education and teaching, we should take students as the foundation, understand their physical and mental development rules, respect students' differences, and improve their learning initiative and local culture identity.

\section{Practical exploration on the transformation and utilization of resources through the path of Art Education}

On the premise of constructing high-quality art education resources and teaching staff, relying on Hakka cultural resources to establish art education $2+1$ mode curriculum system and flexible teaching system is the key to construct the innovative mode of art education with Jiangxi characteristics. The flexibility and variability of teaching system mainly lies in the instability of teaching methods, teaching resources and teaching places, which are changed by students, teachers and time. According to the author's preliminary research on the transformation of Hakka cultural resources into art education, the specific implementation process is as follows:

\subsection{Transforming Hakka cultural resources into Curriculum Resources}

Taking Hakka cultural resources as the research content, the research effect of "research is useful, research can be used. Closely around the background of art education and Hakka culture, combined with innovation and entrepreneurship, through revising the talent training program, introducing Hakka culture into the teaching links 
such as in-course practice, professional training and professional elective courses, creating original ideas and characteristics, and achieving good results in the practice process.

In addition, the program of practice loop in the course is to go into the field to understand the local culture and create works with local cultural background knowledge combined with the course content. We should give full play to the professional expertise of art teachers, add a series of elective courses of intangible cultural heritage in addition to the original general education courses, and add practical links in the curriculum. For example, "Hakka folk art", "Hakka folk song", "Hakka lantern making skills", "Hakka folk color painting" and other courses, the national
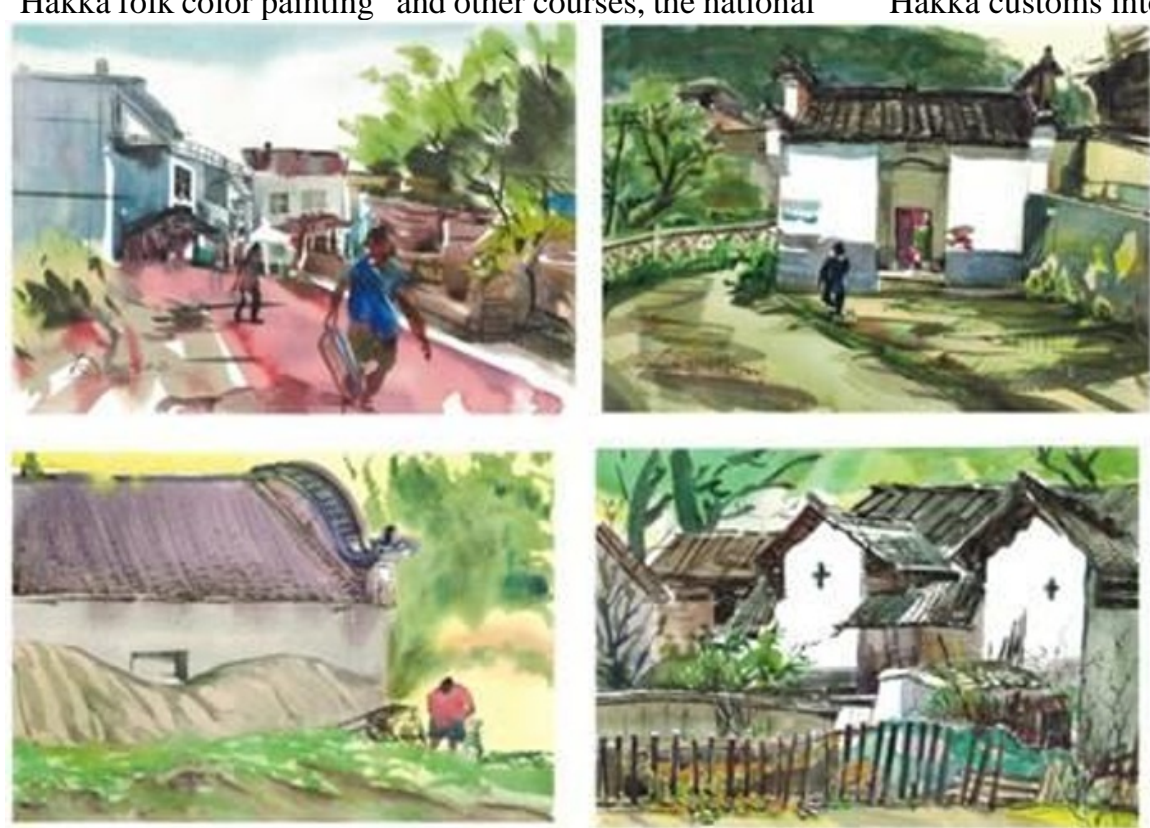

Figure 1. Watercolor works in Hakka folk art classroom

\subsection{Transforming cultural elements into cultural creativity}

Focusing on Hakka needlework culture, creative concept design and innovative design application of Hakka needlework culture, we will shape Hakka needlework cultural and creative brand IP. Through the results of College Students' Entrepreneurship and innovation training program and the cultural and creative product development results of Ganxian County women's red association by Gannan Hakka culture Digital Research Institute, the innovative design of Hakka needlework cultural and creative products is carried out, and the brand
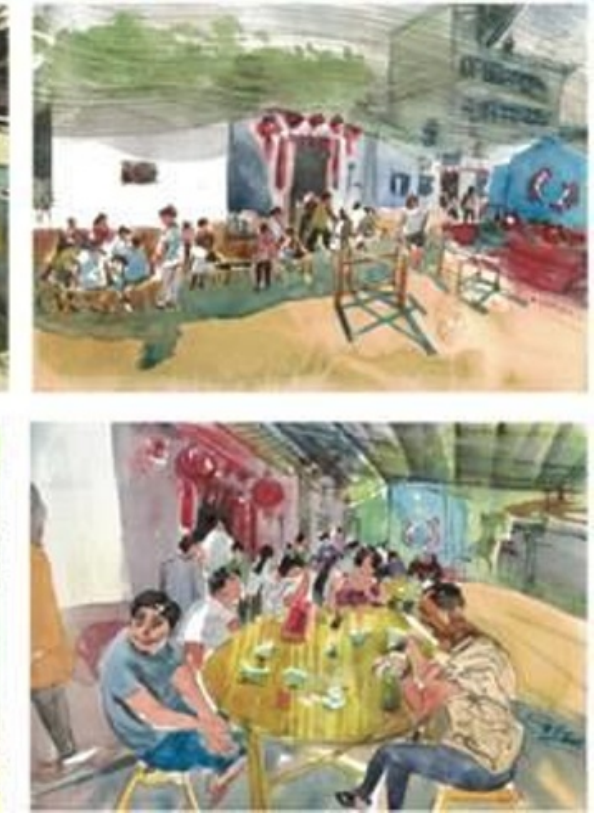

design strategy of Hakka needlework cultural and creative

intangible cultural heritage projects such as handmade lantern making skills in Hakka area and Gannan Tea Picking Opera are integrated into the curriculum system. Taking "Hakka cultural experience + quality cultivation + innovative practice" as the training goal, the course orientation is defined, the course content is selected, and the teaching methods are determined, and a scientific teaching evaluation system is established. The picture below shows the course of "Hakka folk art". The teacher guides the students to sketch the watercolor works by filed sketch, explains the life segments of Hakka people, and applies vivid life scene cases to teach students the cultural knowledge of Hakka architecture, Hakka culture and Hakka customs into painting techniques. products is created. As a combination of culture and economy, the research on innovative design strategy of Hakka needlework cultural and creative industry must take creative production and application as the core. The most critical elements are creative management, brand construction, cultural and creative product development and design. It also needs strong support from university teaching and scientific research. The research on innovative design countermeasures of Hakka needlework artistic and cultural creative products can be roughly divided into: visual cultural and creative product design, needlework cultural and creative IP image design, and two main categories of physical display. 

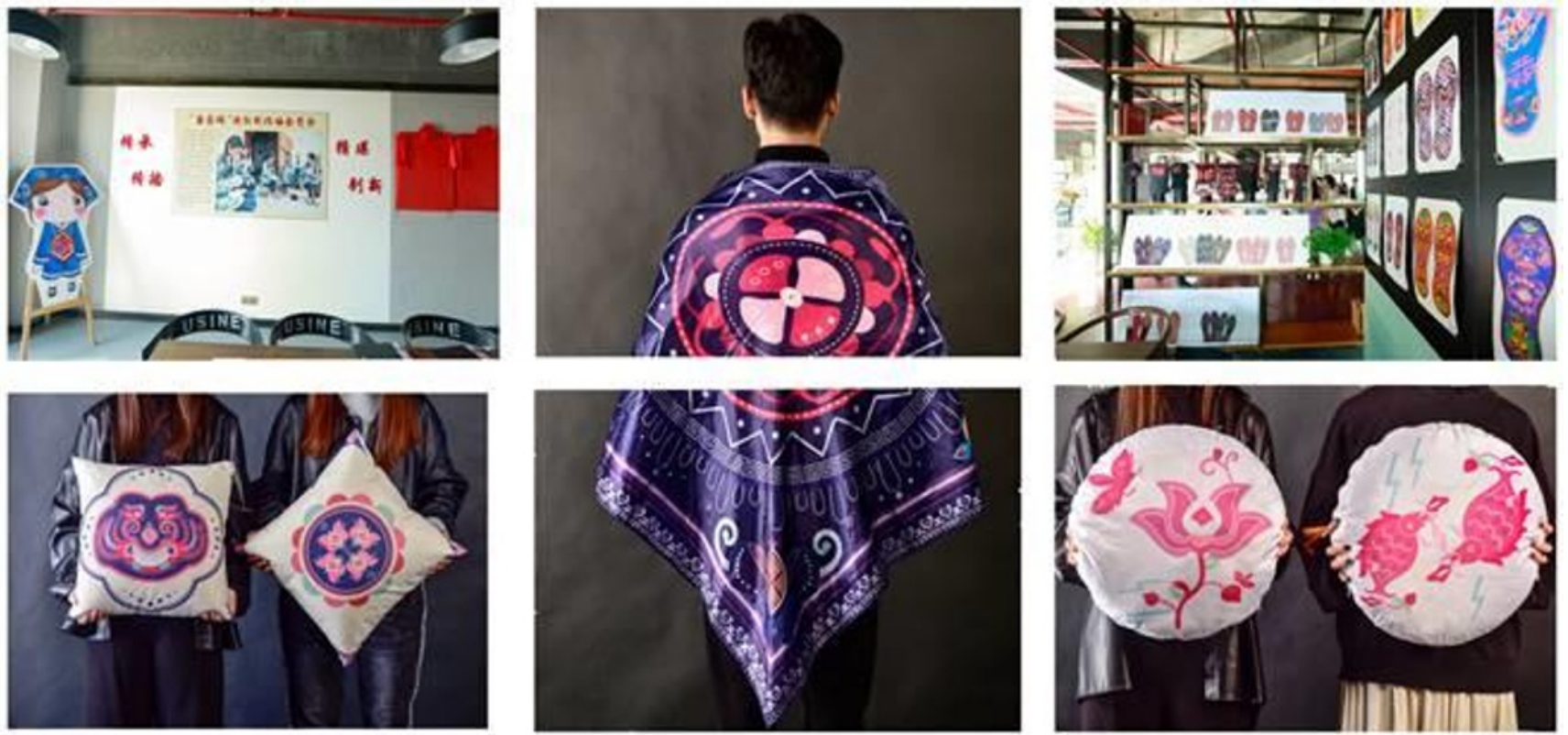

Figure 2. Creative design of Hakka needlework culture

\subsection{Hakka culture and art education research platform}

In order to promote the development of Gannan Hakka culture, give full play to the advantages of local universities in discipline construction, personnel training, scientific research and other fields, meet the needs of science and technology and talents for the rapid development of Gannan Hakka cultural industry, make full use of Gannan's favorable conditions in regional culture, science and technology, industry, capital and demand, and form a win-win mechanism of industry university research cooperation. With the strong support of the Cultural Department of Jiangxi Province, Gannan Hakka culture digital research base was established in 2016, aiming to accumulate rich experience in scientific research projects and provide a good research environment. Since the investigation of the relationship between Hakka cultural resources and art education in Colleges and universities, the research on teachers is classified according to different levels of scientific research ability. For different levels of teachers, the setting of research objectives has different pertinence. The teaching effect of different levels can be compared, and different goals of different schools can be set, which provides the object of comparative study. Gannan Hakka culture Digital Research Institute has a team of teachers with strong educational and scientific research ability, which is composed of design teachers and scientific researchers. The age structure of the main participants is reasonable, and the professional titles and specialties are balanced. They all have different strengths, which provides teachers' guarantee for the implementation of research.

\section{Conclusion}

The establishment of the classic brand of Hakka cultural resources is the source of the cultivation of high-quality art education resources in our province. To establish brand awareness and strive to create high-quality products, make Hakka art education brand promote the formation of characteristics and quality improvement of art education in Colleges and universities, so as to give full play to its multiple effects in culture, economy, education and so on.

\section{Reference}

1. Zeng fanren. A comparative study of public art education in modern Chinese and western universities [M]. Beijing: Economic Science Press, January 2009.

2. Feng Lanfang. Review and Prospect of art education in Colleges and universities in the past 20 years (1978-1998) [J]. People's music, 1999-6.

3. Zhang Daoyi. Art Education in Colleges and universities [J]. Chinese art education, May 1995

4. Arthur Avlan. Translated by Li Xing. A history of Western Art Education [M]. Sichuan: Sichuan people's publishing house, August 2000

5. Brown Kozanik. Translated by Ma Zhuanghuan. Art Creation and Art Education [M]. Sichuan: Sichuan People's Publishing House, 2000.08.

6. Cui Huade Gardner. Multiple intelligences [M]. Beijing: Xinhua Publishing House, 1999.

7. Susan Langer (SusanneK.Langer,1895-1982). Art Problems -- A Cluster of Advanced Discussions on Art Education [M]. Jiangsu: Nanjing press, 2006-11.

8. Cai Ping. Exploring the artistic path of transforming red resources into educational resources $[\mathrm{J}]$. Journal of Jinggangshan University (SOCIAL SCIENCE EDITION), September 2011.

9. Li Kangping. Research on the development and education of Hakka resources in Jiangxi Province: A Study on the history and culture of Jiangxi Hakka [M]. Beijing: China Social Sciences Press, June 2011.

10. He Xiang. Research on the application and value of Xinjiang ethnic and folk arts resources in fine arts 
curriculum of normal universities [J]. literature and art research December 2007.

11. Ministry of Education. National School Art Education Development Plan (2011-2020) [R]. 2012.

12. Feng Yongfu. Integrated application of school education and Hakka culture in architectural design [J]. Chinese folk house, 2014 (7): 23.

13. Li Jing. On the implementation path of aesthetic education in primary and secondary school curriculum $[\mathrm{J}]$. Curriculum, teaching materials and teaching methods, 2015 (12): 22-28. 